Published in final edited form as:

Obes Surg. 2008 September ; 18(9): 1089-1096. doi:10.1007/s11695-008-9454-6.

\title{
The Effect of Laparoscopic Gastric Banding Surgery on Plasma Levels of Appetite-Control, Insulinotropic, and Digestive \\ Hormones
}

\author{
Joshua R. Shak, \\ Department of Medicine, NYU School of Medicine, New York, NY, USA \\ Jatin Roper, \\ Department of Medicine, NYU School of Medicine, New York, NY, USA \\ Guillermo I. Perez-Perez, \\ Department of Medicine, NYU School of Medicine, New York, NY, USA \\ Chi-hong Tseng, \\ Department of Medicine, University of California, Los Angeles, CA, USA

\section{Fritz Francois,} \\ Department of Medicine, NYU School of Medicine, New York, NY, USA, VA NY Harbor \\ Healthcare System, New York, NY, USA
}

\section{Zoi Gamagaris,}

Department of Medicine, NYU School of Medicine, New York, NY, USA, Department of Medicine, Bellevue Hospital Center, New York, NY, USA

\section{Carlie Patterson,}

Department of Medicine, Bellevue Hospital Center, New York, NY, USA

Elizabeth Weinshel,

Department of Medicine, NYU School of Medicine, New York, NY, USA, VA NY Harbor

Healthcare System, New York, NY, USA

\section{George A. Fielding,}

Department of Surgery, NYU School of Medicine, New York, NY, USA

Christine Ren, and

Department of Surgery, NYU School of Medicine, New York, NY, USA

\section{Martin J. Blaser}

Department of Medicine, NYU School of Medicine, New York, NY, USA, VA NY Harbor

Healthcare System, New York, NY, USA

Martin J. Blaser: Martin.Blaser@med.nyu.edu

\begin{abstract}
Background-We hypothesized that laparoscopic adjustable gastric banding (LAGB) reduces weight and modulates ghrelin production, but largely spares gastrointestinal endocrine function.
\end{abstract}

Correspondence to: Martin J. Blaser, Martin. Blaser@med. nyu . edu.

Electronic supplementary material The online version of this article (doi:10.1007/s11695-008-9454-6) contains supplementary material, which is available to authorized users.

Disclosures GAF and CR are consultants for Inamed, Inc. (Irvine, CA), the manufacturer of the Lap-Band device. The other authors have no conflicts of interest. 
To examine this hypothesis, we determined plasma concentrations of appetite-control, insulinotropic, and digestive hormones in relation to LAGB.

Methods-Twenty-four patients undergoing LAGB were prospectively enrolled. Body mass index (BMI) was measured and blood samples obtained at baseline and 6 and 12 months postsurgery. Plasma concentrations of leptin, acylated and total ghrelin, pancreatic polypeptide (PP), insulin, glucose-dependent insulinotropic peptide (GIP), active glucagon-like peptide-1 (GLP-1), gastrin, and pepsinogens I and II were measured using enzyme-linked immunoassays.

Results-Median percent excess weight loss (\%EWL) over 12 months was $45.7 \%$ with median BMI decreasing from 43.2 at baseline to 33.8 at 12 months post-surgery $(p<0.001)$. Median leptin levels decreased from $19.7 \mathrm{ng} / \mathrm{ml}$ at baseline to $6.9 \mathrm{ng} / \mathrm{ml}$ at 12 months post-surgery $(p<0.001)$. In contrast, plasma levels of acylated and total ghrelin, PP, insulin, GIP, GLP-1, gastrin, and pepsinogen I did not change in relation to surgery $(p>0.05)$. Pepsinogen II levels were significantly lower 6 months after LAGB but returned to baseline levels by 12 months.

Conclusions-LAGB yielded substantial \%EWL and a proportional decrease in plasma leptin. Our results support the hypothesis that LAGB works in part by suppressing the rise in ghrelin that normally accompanies weight loss. Unchanged concentrations of insulinotropic and digestive hormones suggest that gastrointestinal endocrine function is largely maintained in the long term.

\section{Keywords}

Obesity; Weight loss; Bariatric surgery; Adjustable gastric banding; Ghrelin; Leptin; GIP; GLP-1

\section{Introduction}

Obesity is a growing public health concern with an estimated 32.2\% of adult Americans currently affected [1]. Bariatric surgeries such as Roux-en-Y gastric bypass (RYGB) and laparoscopic adjustable gastric banding (LAGB) have become increasingly common treatment options [2] and result in long-term weight loss and decreased mortality [3, 4]. Although LAGB has been considered a purely restrictive procedure, optimal placement of an adjustable gastric band not only decreases the size of the meal that can be accommodated, but also changes eating behavior [5,6] and increases post-meal and fasting satiety [7] by pathways not yet elucidated. Therefore, although LAGB decreases body mass index (BMI) [8], the mechanisms involved may be in addition to its restrictive properties on gastric accommodation.

The gastrointestinal tract produces an array of peptide hormones that regulate energy homeostasis [9] and, consequently, may affect weight loss after bariatric surgery. Weight loss after diet or exercise results in a substantial increase in circulating levels of the appetitestimulating hormone ghrelin [10-12] and, often, is temporary. Studies examining circulating ghrelin levels after bariatric surgery have produced varying results, with some studies showing increases [11,13-17, 20], other studies showing decreases [10,11, 18, 19], and additional studies showing unchanged plasma concentrations [15, 20,21].

Conflicting data on the effect of LAGB on ghrelin levels have highlighted the need for additional longitudinal studies with larger sample sizes. In addition, it remains unknown whether unchanged ghrelin levels after LAGB are indicative of preserved or diminished gastric endocrine function. Although RYGB causes changes in insulinotropic [23-26] and gastric hormones [27, 28], circulating concentrations of these hormones have not been evaluated in LAGB subjects in relation to changes in leptin and ghrelin.

Helicobacter pylori, a persistent, lifelong colonizer of the human stomach, has been shown to influence gastric endocrine function. H. pylori-positive subjects have been reported to 
have lower gastric and circulating ghrelin and leptin levels [29-33]. Whether weight loss or gastric hormonal function after LAGB is related to $H$. pylori status has not been examined.

We hypothesized that LAGB facilitates weight loss partly by suppressing an expected rise in ghrelin, but largely spares gastrointestinal endocrine function and is indifferent to $\mathrm{H}$. pylori status. Our aims were to measure BMI and plasma concentrations of representative hormones before and 6 and 12 months after LAGB.

\section{Materials and Methods}

\section{Study Population}

Adults $\geq 18$ years of age with a BMI $\geq 35$ referred for adjustable gastric banding surgery with a Lap-Band device (Inamed, Inc., Irvine, CA, USA) at New York University Medical Center (NYUMC) between April 2003 and April 2006 were prospectively enrolled. Written informed consent was obtained from all subjects.

\section{Data and Sample Collection}

Patients were instructed to fast for at least $8 \mathrm{~h}$ before morning blood samples and height and weight measurements were obtained. Patients served as their own controls, with blood samples and measurements obtained before surgery (median 9, interquartile range [IQR] 318 days before surgery) as well as 6 months (median 187, IQR 181-207 days) and 12 months (median 396, IQR 367- 439 days) after LAGB surgery. Plasma samples were then stored at $-20^{\circ} \mathrm{C}$ until examined. Percent excess weight loss (\%EWL) was calculated using the formula for ideal body weight of Robinson et al. [34].

\section{Plasma Assays}

Single-hormone EIAs Plasma concentrations of leptin, total ghrelin, pepsinogens I and II were measured using specific enzyme-linked immunoassays (EIAs). Standards, controls, and samples were assayed in duplicate on each plate. All samples were assayed on two to three different days and the median used to reflect the final value. Plasma leptin concentrations were determined by a sandwich immunoassay (R\&D Systems; Minneapolis, MN, USA), which has a $3.2 \%$ intra-assay variability and a $4.1 \%$ inter-assay variability, as reported by the manufacturer. As BMI is strongly correlated with morning fasting leptin levels [35], many studies of leptin physiology have utilized fasting determinations of circulating leptin levels [36]. Total ghrelin concentrations were determined with a competitive immunoassay (Phoenix Pharmaceuticals, Inc., Burlingame, CA, USA) with intra- and inter-assay variabilities of 5\% and $14 \%$, respectively. Although mealtime variation in ghrelin plays an important role in appetite regulation, the strong correlation $(\mathrm{r}=0.87, p=0.0004)$ between pre-breakfast fasting levels and 24-h integrated values indicates that morning ghrelin levels are reliable indicators of day-long integrated ghrelin levels [37]. Pepsinogen I and II concentrations were measured with immunoassays from BioHIT PLC (Helsinki, Finland). As reported by the manufacturer, the pepsinogen I assay has intra- and inter-assay variabilities of $3.4 \%$ and $3.6 \%$, respectively, and the pepsinogen II assay has intra-and inter-assay variabilities of $4.8 \%$ and $3.0 \%$, respectively. Gastrin concentrations were determined by immunoassay (Quest Diagnostics Inc. Lyndhurst, NJ, USA).

Multi-hormone panel A multi-hormone EIA panel (Linco Research, Billerica, MA, USA) was used to measure plasma concentrations of insulin, leptin, acylated ghrelin, total glucosedependent insulinotropic peptide (GIP), active glucagon-like peptide-1 (GLP-1), and pancreatic polypeptide (PP). As leptin concentrations measured by the multi-hormone panel correlated significantly $(r=0.85, \mathrm{p}<0.001)$ with the concentrations obtained by specific EIA, the values obtained by specific EIA were used in all further analyses unless stated otherwise. 
As reported by the manufacturer, this multi-hormone panel has intra- and inter-assay variabilities of $11 \%$ and $19 \%$, respectively.

H. pylori antibody EIAs Plasma samples were evaluated for immunoglobulin $\mathrm{G}$ (IgG) antibodies to $H$. pylori whole cell antigens by a previously described [38] antigen-specific EIA with mean, SD, and coefficient of variation of $1.83 \%, 0.26 \%$, and $14.2 \%$, respectively [38]. Plasma samples were diluted 1:100 and assayed in duplicate. An absorbance index (AI) was calculated from mean absorbance at $405 \mathrm{~nm}$ of two assays per sample, in relation to reference plasma. A previously validated threshold (AI>1.0) was used to define H. pylori seropositivity [39]. CagA status was determined by an EIA based on the presence of plasma IgG antibodies against orv220, a 65,000-Da recombinant cagA-encoded protein purified from Escherichia coli [40]. A previous evaluation of this assay determined that the mean, $\mathrm{SD}$, and coefficient of variation were $0.15 \%, 0.04 \%$, and $26.7 \%$, respectively [38]. CagA seropositivity (representing carriage of a cag $A+$ strain) was defined as an optical density ratio $>0.35$, as validated previously [40].

\section{Statistical Analysis}

Descriptive statistics were generated for baseline demographics to characterize the study participants, using medians with IQR for continuous variables and frequency distribution for categorical variables. For hypothesis testing, Wilcoxon rank sum test was used to compare continuous variables and Fisher's exact test for categorical variables. Wilcoxon signed rank test also was used to evaluate the difference of paired data. Spearman correlations were used to evaluate correlations between \%EWL over 6 and 12 months and baseline hormone levels as well as percent change in hormone levels. All tests were two-sided, and $p$ values less than 0.05 were considered significant.

\section{Results}

\section{Characteristics of the Study Population and \%EWL after LAGB}

Approximately 1,200 individuals attended information sessions on LAGB at NYUMC and received written information about enrollment in this study. Of the 58 patients who responded, 27 were unable to participate because of lack of insurance coverage or scheduling conflicts with the General Clinical Research Center. Of the 31 enrolled subjects, seven had not yet had a follow-up visit; the remaining 24 patients were the subjects of this study. Of the 24 patients enrolled, two did not have a 6-month follow-up, and two had not yet had a 1-year follow-up.

For the study population as a whole, the median age at the time of surgery was 46.6 (IQR 34.5-50.6) years, and the median BMI was 43.2 (IQR 40.4-49.6). At baseline, there was no statistically significant difference between five $\mathrm{H}$. pylori-positive and $19 \mathrm{H}$. pylori-negative subjects in age, BMI, weight, or excess weight (Table 1).

The Lap-Band surgery was successful; for the study population as a whole, \%EWL was 31.2 (23.1-37.5) at 6 months and 45.7 (39.1-52.3) at 12 months after LAGB. BMI decreased significantly $(p<0.001)$ from the baseline median of $43.2(40.4-48.5)$ to $34.4(32.4-39.4)$ at 6 months and 33.4 (30.2-36.2) at 12 months (Fig. 1a; Supp Table 1).

\section{Appetite-Control Hormone Levels in Relation to LAGB}

Baseline BMI was strongly correlated with baseline leptin levels as assessed by specific EIA $(r=0.48, p=0.02$; Fig. $2 \mathrm{a})$ and by the Lincoplex panel $(r=0.62, p=0.001$, Fig. $2 \mathrm{~b})$. Baseline excess body weight also was correlated with baseline leptin as measured by specific EIA $(r=0.48, p=0.02)$ and Lincoplex panel $(r=0.65, p<0.001)$. The leptin values obtained by 
specific EIA and by the Lincoplex panel were strongly correlated ( $r=0.57, p=0.004$, Fig. $2 c)$. Plasma leptin concentrations (nanograms per milliliter), as assessed by specific EIA, decreased from the baseline median of 19.7 (IQR 15.1-23.4) to a median of 11.4(7.7-16.1) 6 months post-surgery $(p<0.001)$ and to a median of $6.9(5.8-13.2) 12$ months post-surgery ( $p<0.001$; Fig. 1b; Supp Table 1). The continued decrease in leptin levels between 6 and 12 months after surgery was not significant $(p=0.31)$.

In relation to surgery, there were no significant changes in the plasma concentration of PP (Fig. 1e). Baseline PP levels and change in PP over 12 months were not correlated with $\%$ EWL over 12 months.

Acylated ghrelin concentrations at 6 and 12 months were not significantly different from baseline levels (Fig. 1c; Supp Table 1). Similarly, total ghrelin concentrations at 6 and 12 months were not significantly different from the baseline ghrelin concentrations (Fig. 1d; Supp Table 1). In relation to surgery, there were no significant changes in the acylated/total ghrelin ratio (Supp Table 1). Baseline acylated and total ghrelin levels and change in acylated and total ghrelin levels over 12 months were not correlated with \%EWL over 12 months (Supp Table 1).

When the patient population was stratified into two groups based on \%EWL over 12 months (Supp Fig. 1a), there was no significant difference between the groups in total ghrelin, acylated ghrelin, or acylated/total ghrelin at any time point (Supp Fig. 1b, c, d). The patient population also was stratified into two groups based on those with low acylated ghrelin that remained low during the study period $(<350 \mathrm{pg} / \mathrm{ml} ; n=10)$ and those with high initial and continuing high acylated ghrelin $(>350 \mathrm{pg} / \mathrm{ml} ; n=11)$. One subject with intermediate values was excluded from this analysis. These two groups did not differ significantly in initial BMI, BMI after 12 months, or in \%EWL (data not shown). We also stratified the population based on presurgery ratios of acylated/total ghrelin, dividing the population into a high group $(>0.65 ; n=10)$ and a low group $(<0.2, n=13)$. Again, there were no significant differences in BMI or \%EWL (data not shown).

\section{Insulinotropic Hormone Levels in Relation to LAGB}

Before surgery, median (IQR) plasma concentrations (pg/ml) of insulin, GIP, and GLP-1 were 209 (144-419), 3.24 (1.54- 7.63), and 81.6 (2.6-81.3), respectively. Concentrations of insulin, GIP, and GLP-1 did not change significantly in relation to surgery (Fig. 1f-h; Supp Table 1). Baseline concentrations and change in concentration of insulin, GIP, and GLP-1 also were not correlated with \%EWL in the 12 months after surgery.

\section{Digestive Hormone Levels in Relation to LAGB}

After surgery, plasma concentrations of gastrin and pepsinogen I were not significantly different from the baseline values of $31.0(26.5-46.0) \mathrm{pg} / \mathrm{ml}$, and $53.1(41.5-69.6) \mathrm{ng} / \mathrm{ml}$, respectively (Fig. 1i, j). There was a significant $(p=0.01)$ decrease in pepsinogen II from the baseline concentration (nanograms per milliliter) of 4.77 (3.57-5.67) to $3.57(2.87-4.96)$ at 6 months (Fig. 1k). However, 12 months after surgery, pepsinogen II levels were not significantly different from baseline values. Similarly, the pepsinogen I/II ratio before surgery, 11.8 (10.3-13.3), was significantly different from the ratio at 6 months, but not different from the ratio at 12 months (Fig. 11). Baseline concentrations of gastrin, pepsinogen I, pepsinogen II, and the pepsinogen I/II ratio and percent changes in these values were not correlated with \%EWL over 12 months. 


\section{Relation of $\boldsymbol{H}$. pylori Status to \%EWL and Hormone Levels}

Comparison of the five subjects who were $H$. pylori-positive and the 19 subjects who were H. pylori-negative preoperatively revealed no significant differences in leptin, acylated ghrelin, total ghrelin, acylated/total ghrelin ratio, insulin, GIP, GLP-1, gastrin, pepsinogen I, pepsinogen II, or pepsinogen I/II ratio (Supp Table 2). However, before surgery, H. pyloripositive subjects had significantly $(p=0.02)$ higher plasma PP concentrations $(49.6,45.7-$ 97.6) than the $H$. pylori-negative subjects (27.8, 1.2-40.1, Supp Table 2). After surgery, PP levels remained significantly ( $p=0.01$ ) higher in the H. pylori-positive group at 6 months. However, at 12 months, although $\mathrm{H}$. pylori-positive subjects had higher plasma PP concentrations than $H$. pylori-negative subjects, the difference was not significant ( $p=0.07$; Supp Table 2).

Comparison of the $H$. pylori-positive and $H$. pylori-negative subjects at 6 and 12 months post-surgery revealed no significant differences in leptin, acylated ghrelin, total ghrelin, acylated/total ghrelin ratio, insulin, GIP, GLP-1, gastrin, pepsinogen I, or pepsinogen I/II ratio (Supp Table 2). However, 12 months after surgery, pepsinogen II concentrations were significantly ( $\mathrm{p}=0.01$ ) higher in the $H$. pylori-positive subjects than the $H$. pylori-negative subjects. There also was no significant difference in \%EWL, over 6 or 12 months, by $H$. pylori status.

\section{Discussion}

In this study, patients served as their own controls; longitudinal studies control for inter-host variation that is introduced by between-group ecological studies. The observed \%EWL (median 45.7; IQR 39.1-52.6) in the 12 months after LAGB is consistent with the results of a meta-analysis of 25 studies that found a median 47.5\%EWL (IQR 40.7-54.2) after LAGB [8]. Circulating leptin levels decreased along with BMI, likely due to loss of leptinproducing adipocytes. The strong correlation between baseline excess body weight and baseline leptin is consistent with the contention that percentage body fat is the most important factor in leptin production [35]. In addition, the strong correlation between BMI and leptin values obtained by both specific EIA and the Lincoplex multi-hormone panel and with BMI (Supp Fig. 1c) support both assays as accurate indicators of plasma leptin levels.

There has been much contention over the role of the orexogenic hormone ghrelin in the outcomes of various weight-loss modalities. It has been suggested that a rise in ghrelin after diet-induced weight loss $[10,11]$ may explain why weight is often regained. A landmark study of five RYGB patients [10] found that plasma levels of ghrelin decreased drastically after RYGB, suggesting that changes in ghrelin dynamics may be partially responsible for the success of that procedure. However, additional studies of circulating ghrelin in relation to RYGB have yielded varying results. A review of 11 such studies [41] showed that six papers have reported decreases in ghrelin, four papers have reported unchanged ghrelin, and one 66-subject study reported increases in ghrelin after RYGB [13].

Similarly, there have been differing reports on the effect of LAGB on circulating ghrelin levels. Whereas some studies have reported an increase in plasma ghrelin after LAGB [11, 14-17], others have reported unchanged ghrelin [21]. In addition, a cross-sectional study of subjects who had undergone gastric banding 9-15 months previously found that banding patients had significantly lower plasma ghrelin levels than normoweight and obese controls [18]. A recent study of the relationship between LAGB and plasma leptin in obese Zucker rats [22] has suggested that, in a standardized system, ghrelin levels remain constant after surgery. With our study's larger subject group $(n=24)$, assessment of acylated and total ghrelin, and multiple independent measurements of the amount of total ghrelin in each 
plasma sample, we aimed to decrease variation often caused by small sample size and interassay variability.

Our observation that fasting levels of both acylated and total ghrelin levels were unchanged after LAGB-induced weight-loss suggests that this surgery has a direct effect on ghrelin production. Because fasting levels of ghrelin are strongly correlated with area-under-thecurve (AUC) measurements [37], our results suggest that 24-h integrated levels of ghrelin after surgery are not significantly different from pre-surgery AUC values. Because AUC ghrelin has been shown to normally increase after weight loss [10], the observed suppression in the rise of ghrelin may explain why LAGB patients experience greater weight loss than patients undergoing nonsurgical treatment [42]. The placement of a band around the stomach may impair the function of the ghrelin-producing cells in the fundus or alter the way in which ghrelin production is stimulated. This hypothesis is supported by the transient, but significant, decrease in circulating pepsinogen II that we observed 6 months after LAGB. Thus, the conflicting results of previous studies on circulating ghrelin levels after LAGB and RYGB may be a result of differences in surgical technique.

The results of our study do not support the theory that changes in circulating ghrelin explain the reported increase in satiety after LAGB [7]. However, decreased appetite after LAGB could be caused by altered mealtime changes in ghrelin, as has been reported for RYGB [43]; this hypothesis warrants future study. Although PP has been shown to inhibit appetite and food intake [45], our findings do not support a role for PP in LAGB-induced weight loss, consistent with data from studies on other bariatric procedures [26, 27]. Our data do not support the hypothesis that fasting ghrelin levels before surgery are a predictor of weight loss after LAGB, in agreement with a previous report [44].

Our study suggests that LAGB does not affect insulin and incretin hormone homeostasis. In contrast, after RYGB, fasting levels of GIP increase [46], and mealtime dynamics of GLP-1 change in a way that enhances satiety as reported in other studies [26, 47]. Future studies of meal-time changes in GIP and GLP-1 after gastric banding also would be useful. The constant levels of gastrin and pepsinogen I levels after surgery suggest that LAGB largely spares gastric endocrine function. In contrast, decreased plasma concentrations of pepsinogen I levels after RYGB [27] suggest that the procedure may induce atrophy.

The results of our study suggest that weight loss and gastrointestinal endocrine function after LAGB are not dramatically affected by $H$. pylori status. Although the differences between H. pylori-positive and H. pylori-negative subjects in PP and pepsinogen II were statistically significant (Supp Table 2), further studies with a greater number of $H$. pylori-positive subjects should be conducted before firm conclusions can be reached. A previous study of normal-weight dyspeptic and healthy subjects [48] found no difference between $H$. pyloripositive and $H$. pylori-negative subjects in plasma PP levels. As morbid obesity is inversely correlated with gastric $H$. pylori colonization [49], further study on the effect of $H$. pylori colonization on appetite-control hormones such as PP is needed.

Our study cannot determine whether the changes in hormone levels we observed after LAGB are a result or a cause of the weight loss. This study is also limited by its lack of nonbanded weight-matched controls. However, the longitudinal nature of our study, and the breadth of circulating peptides studied, allows our results to be informative about three different classes of peptides (appetite-control, insulinotropic, and digestive) in relation to LAGB. As only fasting plasma samples were obtained, we did not examine whether LAGB affects mealtime changes in appetite-control hormone levels, which could account for the reduction in appetite post-surgery. Future studies should explore this hypothesis. 
Overall, the results of this study are consistent with the hypothesis that gastric banding works in part by suppressing the rise in orexogenic ghrelin that normally accompanies weight loss. In contrast to RYGB, which has long-term effects on glucose homeostasis [50] and digestive hormone secretion [27], we found that LAGB largely spared gastrointestinal endocrine function over 1 year. Our findings may assist patients and clinicians in choosing between the two surgical weight loss modalities and help clarify the pathophysiologic mechanisms involved.

\section{Supplementary Material}

Refer to Web version on PubMed Central for supplementary material.

\section{Acknowledgments}

This study is supported in part by RR00096, K23CA107123 from the National Institute of Health, the Diane Belfer Program for Human Microbial Ecology, and the Michael Saperstein Medical Scholars Program. The authors thank Drs. Frank Martiniuk and Maryann Huie for performing the Lincoplex assay.

\section{References}

1. Ogden CL, Carroll MD, Curtin LR, McDowell MA, Tabak CJ, Flegal KM. Prevalence of overweight and obesity in the United States, 1999-2004. JAMA. 2006; 295:1549-55. [PubMed: 16595758]

2. Santry HP, Gillen DL, Lauderdale DS. Trends in bariatric surgical procedures. JAMA. 2005; 294:1909-17. [PubMed: 16234497]

3. Sjostrom L, Narbro K, Sjostrom CD, et al. Effects of bariatric surgery on mortality in Swedish obese subjects. N Engl J Med. 2007; 357:741-52. [PubMed: 17715408]

4. Adams TD, Gress RE, Smith SC, et al. Long-term mortality after gastric bypass surgery. N Engl J Med. 2007; 357:753-61. [PubMed: 17715409]

5. Elder KA, Wolfe BM. Bariatric surgery: a review of procedures and outcomes. Gastroenterology. 2007; 132:2253-71. [PubMed: 17498516]

6. Lang T, Hauser R, Buddeberg C, Klaghofer R. Impact of gastric banding on eating behavior and weight. Obes Surg. 2002; 12:100-7. [PubMed: 11868284]

7. Dixon AF, Dixon JB, O'Brien PE. Laparoscopic adjustable gastric banding induces prolonged satiety: a randomized blind crossover study. J Clin Endocrinol Metab. 2005; 90:813-9. [PubMed: 15585553]

8. Buchwald H, Avidor Y, Braunwald E, et al. Bariatric surgery: a systematic review and metaanalysis. JAMA. 2004; 292:1724-37. [PubMed: 15479938]

9. Crowell MD, Decker GA, Levy R, Jeffrey R, Talley NJ. Gut-brain neuropeptides in the regulation of ingestive behaviors and obesity. Am J Gastroenterol. 2006; 101:2848-56. [PubMed: 17026567]

10. Cummings DE, Weigle DS, Frayo RS, et al. Plasma ghrelin levels after diet-induced weight loss or gastric bypass surgery. N Engl J Med. 2002; 346:1623-30. [PubMed: 12023994]

11. Fruhbeck G, Rotellar F, Hernandez-Lizoain JL, et al. Fasting plasma ghrelin concentrations 6 months after gastric bypass are not determined by weight loss or changes in insulinemia. Obes Surg. 2004; 14:1208-15. [PubMed: 15527636]

12. Purnell JQ, Cummings D, Weigle DS. Changes in 24-h area-under-the-curve ghrelin values following diet-induced weight loss are associated with loss of fat-free mass, but not with changes in fat mass, insulin levels or insulin sensitivity. Int J Obes (Lond). 2007; 31:385-9. [PubMed: 16819531]

13. Holdstock C, Engstrom BE, Ohrvall M, Lind L, Sundbom M, Karlsson FA. Ghrelin and adipose tissue regulatory peptides: effect of gastric bypass surgery in obese humans. J Clin Endocrinol Metab. 2003; 88:3177-83. [PubMed: 12843162]

14. Nijhuis J, van Dielen FM, Buurman WA, Greve JW. Ghrelin, leptin and insulin levels after restrictive surgery: a 2-year follow-up study. Obes Surg. 2004; 14:783-7. [PubMed: 15318982] 
15. Stoeckli R, Chanda R, Langer I, Keller U. Changes of body weight and plasma ghrelin levels after gastric banding and gastric bypass. Obes Res. 2004; 12:346-50. [PubMed: 14981228]

16. Mariani LM, Fusco A, Turriziani M, et al. Transient increase of plasma ghrelin after laparoscopic adjustable gastric banding in morbid obesity. Horm Metab Res. 2005; 37:242-5. [PubMed: 15952085]

17. Hanusch-Enserer U, Cauza E, Brabant G, et al. Plasma ghrelin in obesity before and after weight loss after laparoscopical adjustable gastric banding. J Clin Endocrinol Metab. 2004; 89:3352-8. [PubMed: 15240614]

18. Leonetti F, Silecchia G, Iacobellis G, et al. Different plasma ghrelin levels after laparoscopic gastric bypass and adjustable gastric banding in morbid obese subjects. J Clin Endocrinol Metab. 2003; 88:4227-31. [PubMed: 12970291]

19. Morinigo R, Casamitjana R, Moize V, et al. Short-term effects of gastric bypass surgery on circulating ghrelin levels. Obes Res. 2004; 12:1108-16. [PubMed: 15292475]

20. Faraj M, Havel PJ, Phelis S, Blank D, Sniderman AD, Cianflone K. Plasma acylation-stimulating protein, adiponectin, leptin, and ghrelin before and after weight loss induced by gastric bypass surgery in morbidly obese subjects. J Clin Endocrinol Metab. 2003; 88:1594-602. [PubMed: 12679444]

21. Hanusch-Enserer U, Brabant G, Roden M. Ghrelin concentrations in morbidly obese patients after adjustable gastric banding. N Engl J Med. 2003; 348:2159-60. [PubMed: 12761382]

22. Monteiro MP, Ribeiro AH, Nunes AF, et al. Increase in Ghrelin levels after weight loss in obese zucker rats is prevented by gastric banding. Obes Surg. 2007; 17:1599-607. [PubMed: 18049841]

23. Rubino F, Gagner M, Gentileschi P, et al. The early effect of the Roux-en-Y gastric bypass on hormones involved in body weight regulation and glucose metabolism. Ann Surg. 2004; 240:23642. [PubMed: 15273546]

24. Morinigo R, Lacy AM, Casamitjana R, Delgado S, Gomis R, Vidal J. GLP-1 and changes in glucose tolerance following gastric bypass surgery in morbidly obese subjects. Obes Surg. 2006; 16:1594-601. [PubMed: 17217635]

25. Morinigo R, Moize V, Musri M, et al. Glucagon-like peptide-1, peptide YY, hunger, and satiety after gastric bypass surgery in morbidly obese subjects. J Clin Endocrinol Metab. 2006; 91:173540. [PubMed: 16478824]

26. le Roux CW, Aylwin SJ, Batterham RL, et al. Gut hormone profiles following bariatric surgery favor an anorectic state, facilitate weight loss, and improve metabolic parameters. Ann Surg. 2006; 243:108-14. [PubMed: 16371744]

27. Sundbom M, Mardh E, Mardh S, Ohrvall M, Gustavsson S. Reduction in serum pepsinogen I after Roux-en-Y gastric bypass. J Gastrointest Surg. 2003; 7:529-35. [PubMed: 12763411]

28. Sundbom M, Holdstock C, Engstrom BE, Karlsson FA. Early changes in ghrelin following Rouxen-Y gastric bypass: influence of vagal nerve functionality? Obes Surg. 2007; 17:304-10. [PubMed: 17546836]

29. Isomoto H, Nakazato M, Ueno H, et al. Low plasma ghrelin levels in patients with Helicobacter pylori-associated gastritis. Am J Med. 2004; 117:429-32. [PubMed: 15380500]

30. Jun DW, Lee OY, Lee YY, Choi HS, Kim TH, Yoon BC. Correlation between gastrointestinal symptoms and gastric leptin and ghrelin expression in patients with gastritis. Dig Dis Sci. 2007; 52:2866-72. [PubMed: 17436104]

31. Osawa H, Nakazato M, Date Y, et al. Impaired production of gastric ghrelin in chronic gastritis associated with Helicobacter pylori. J Clin Endocrinol Metab. 2005; 90:10-6. [PubMed: 15483107]

32. Salles N, Menard A, Georges A, et al. Effects of Helicobacter pylori infection on gut appetite peptide (leptin, ghrelin) expression in elderly inpatients. J Gerontol A Biol Sci Med Sci. 2006; 61:1144-50. [PubMed: 17167154]

33. Tatsuguchi A, Miyake K, Gudis K, et al. Effect of Helicobacter pylori infection on ghrelin expression in human gastric mucosa. Am J Gastroenterol. 2004; 99:2121-7. [PubMed: 15554990]

34. Robinson JD, Lupkiewicz SM, Palenik L, Lopez LM, Ariet M. Determination of ideal body weight for drug dosage calculations. Am J Hosp Pharm. 1983; 40:1016-9. [PubMed: 6869387] 
35. Considine RV, Sinha MK, Heiman ML, et al. Serum immunore-active-leptin concentrations in normal-weight and obese humans. N Engl J Med. 1996; 334:292-5. [PubMed: 8532024]

36. Zhang F, Chen Y, Heiman M, Dimarchi R. Leptin: structure, function and biology. Vitam Horm. 2005; 71:345-72. [PubMed: 16112274]

37. Cummings DE, Purnell JQ, Frayo RS, Schmidova K, Wisse BE, Weigle DS. A preprandial rise in plasma ghrelin levels suggests a role in meal initiation in humans. Diabetes. 2001; 50:1714-9. [PubMed: 11473029]

38. Limburg P, Qiao Y, Mark S, et al. Helicobacter pylori seropos-itivity and subsite-specific gastric cancer risks in Linxian, China. J Natl Cancer Inst. 2001; 93:226-33. [PubMed: 11158192]

39. Romero-Gallo J, Perez-Perez GI, Novick RP, Kamath P, Norbu T, Blaser MJ. Responses of endescopy patients in Ladakh, India, to Helicobacter pylori whole-cell and cagA antigens. Clin Diagn Lab Immunol. 2002; 9:1313-7. [PubMed: 12414766]

40. Blaser MJ, Perez-Perez GI, Kleanthous H, et al. Infection with Helicobacter pylori strains possessing cagA is associated with an increased risk of developing adenocarcinoma of the stomach. Cancer Res. 1995; 55:2111-5. [PubMed: 7743510]

41. Cummings DE, Overduin J, Foster-Schubert KE. Gastric bypass for obesity: mechanisms of weight loss and diabetes resolution. J Clin Endocrinol Metab. 2004; 89:2608-15. [PubMed: 15181031]

42. O_Brien PE, Dixon JB, Laurie C, et al. Treatment of mild to moderate obesity with laparoscopic adjustable gastric banding or an intensive medical program: a randomized trial. Ann Intern Med. 2006; 144:625-33. [PubMed: 16670131]

43. Engstrom BE, Ohrvall M, Sundbom M, Lind L, Karlsson FA. Meal suppression of circulating ghrelin is normalized in obese individuals following gastric bypass surgery. Int J Obes (Lond). 2007; 31:476-80. [PubMed: 16924271]

44. Busetto L, Segato G, De Luca M, et al. High ghrelin concentration is not a predictor of less weight loss in morbidly obese women treated with laparoscopic adjustable gastric banding. Obes Surg. 2006; 16:1068-74. [PubMed: 16901362]

45. Batterham RL, Le Roux CW, Cohen MA, et al. Pancreatic polypeptide reduces appetite and food intake in humans. J Clin Endocrinol Metab. 2003; 88:3989-92. [PubMed: 12915697]

46. Clements RH, Gonzalez QH, Long CI, Wittert G, Laws HL. Hormonal changes after Roux-en-Y gastric bypass for morbid obesity and the control of type-II diabetes mellitus. Am Surg. 2004; 70:1-4. [PubMed: 14964537]

47. le Roux CW, Welbourn R, Werling M, et al. Gut hormones as mediators of appetite and weight loss after Roux-en-Y gastric bypass. Ann Surg. 2007; 246:780-5. [PubMed: 17968169]

48. Chiloiro M, Russo F, Riezzo G, et al. Effect of Helicobacter pylori infection on gastric emptying and gastrointestinal hormones in dyspeptic and healthy subjects. Dig Dis Sci. 2001; 46:46-53. [PubMed: 11270793]

49. Wu MS, Lee WJ, Wang HH, Huang SP, Lin JT. A case-control study of association of Helicobacter pylori infection with morbid obesity in Taiwan. Arch Intern Med. 2005; 165:1552-5. [PubMed: 16009873]

50. Schauer PR, Burguera B, Ikramuddin S, et al. Effect of laparoscopic Roux-en-Y gastric bypass on type 2 diabetes mellitus. Ann Surg. 2003; 238:467-84. discussion 84-5. [PubMed: 14530719] 

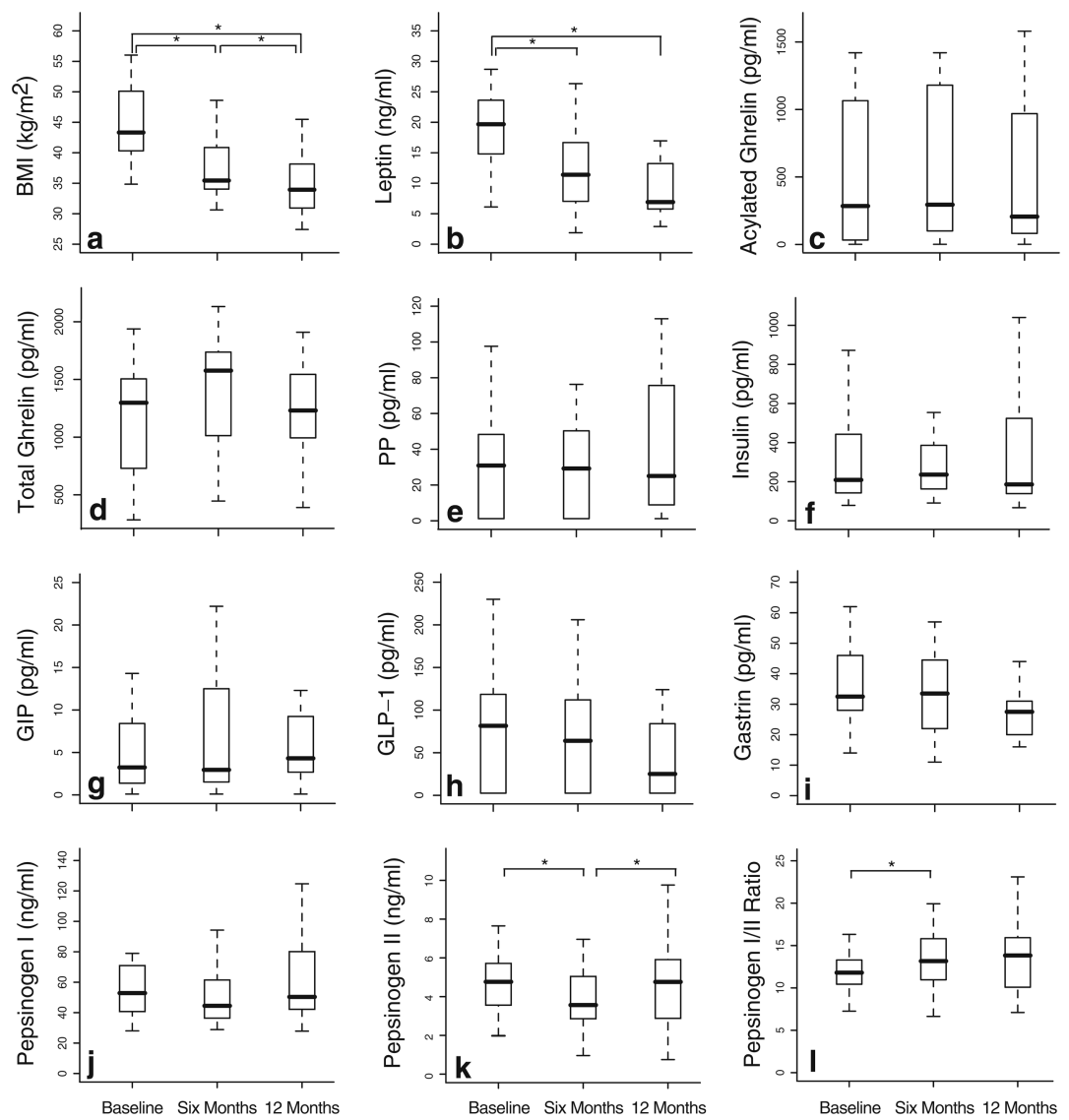

Fig. 1.

BMI and serum peptide levels before and after LAGB. Plots pepsinogen I/II ratio (l).

Boxplots depict the median, IQR, and are of: body mass index (BMI; a), leptin (b), acylated ghrelin (c), total minimum and maximum values at each time point. Baseline, 6-month, ghrelin (d), pancreatic polypeptide $(P P, \mathbf{e})$, insulin (f), glucose- and 12-month values compared pairwise with paired Wilcoxon signed dependent insulinotropic peptide $(G I P, \mathbf{g})$, glucagon-like peptide-1 rank tests, ${ }^{*} p<0.05(G L P-1 ; \mathbf{h})$, gastrin (i), pepsinogen I (j), pepsinogen II (k), and the pepsinogen I/II ratio (1). Boxplots depict the median, IQR, and minimum and maximum values at each time point. Baseline, 6-month, and 12-month values compared pairwise with paired Wilcoxon signed rank tests, ${ }^{*} p<0.05$ 

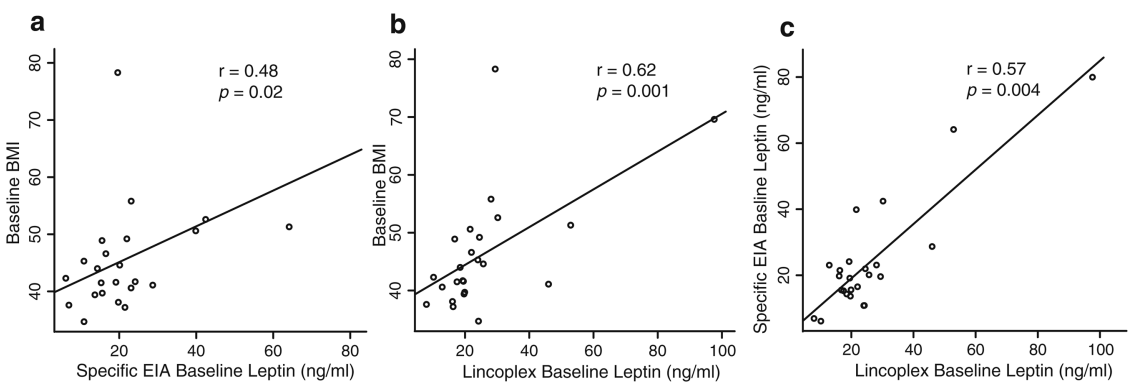

Fig. 2.

Correlation between baseline BMI and baseline leptin as measured by single- and multihormone assays. Plots depict baseline BMI versus specific EIA leptin values (a), Lincoplex panel leptin values (b), and specific EIA versus Lincoplex EIA baseline leptin values (c). Significance determined with Spearman test 
Table 1

Demographic characteristics of study subjects at enrollment, by $\boldsymbol{H}$. pylori status

\begin{tabular}{|c|c|c|c|c|}
\hline & All $(n=24)$ & H. pylori-positive $(\mathrm{n}=5)$ & H. pylori-negative $(\mathrm{n}=19)$ & Significance $p$ value \\
\hline Age $(\text { years })^{a}$ & $46.6(34.5-50.6)$ & $45.5(42.5-59.8)$ & $47.7(34.4-50.1)$ & $0.73^{c}$ \\
\hline $\operatorname{BMI}\left(\mathrm{kg} / \mathrm{m}^{2}\right)^{a}$ & $43.2(40.4-48.5)$ & $42.4(37.5-50.9)$ & $43.9(40.5-47.2)$ & $0.89^{c}$ \\
\hline Height $(\mathrm{cm})^{a}$ & $168(164-174)$ & $173(168-179)$ & $167(162-170)$ & $0.11^{c}$ \\
\hline Weight $(\mathrm{kg})^{a}$ & $128(116-174)$ & $123(121-211)$ & $128(115-136)$ & $0.48^{c}$ \\
\hline Excess weight $(\mathrm{kg})^{a, b}$ & $63.2(51.5-74.6)$ & $59.3(49.5-150.4)$ & $66.2(51.5-74.2)$ & $0.83^{c}$ \\
\hline Gender ( $\%$ male) & 42 & 37 & 60 & $0.61^{d}$ \\
\hline Ethnicity (white/black/Hispanic/other) & $15 / 6 / 2 / 1$ & $3 / 1 / 0 / 1$ & $12 / 5 / 2 / 0$ & $0.37^{d}$ \\
\hline
\end{tabular}

${ }^{a}$ Median (interquartile range)

$b_{\text {Actual minus ideal body weight as described (15) }}$

$c_{\text {Unpaired Wilcoxon test }}$

$d_{\text {Fisher's exact test }}$ 